\section{SKYPE, CODE AND SHOUTING: A Digitally MEDIATED DRAMA BETWEEN EGYPT AND SCOTLAND}

Shabina Aslam, Ankur Theatre Productions, Glasgow, U.K. Email: <shabina.aslam@ankurproductions.org.uk>.

Eleanor Dare, University of Derby, School of Computing and Mathematics, Buxton, U.K. Email: <e.dare@ derby.ac.uk>.

See $<$ www.mitpressjournals.org/toc/leon/48/3> for supplemental files associated with this issue.

\section{Abstract \\ Springtime (Tron Theatre, Glasgow, 19 May 2012) was a computationally mediated theatrical performance involving Arab and Glaswegian-Arab actors and musicians. The project was produced by Ankur Theatre Productions, Scotland's foremost black and ethnic minority theatre company. Springtime was directed by the dramaturge Shabina Aslam. Against the backdrop of the "Arab Spring" and its aftermath, the play explored issues of authenticity and identity as mediated through multiple technologies. This paper explores the impact and significance of the production and evaluates the use of Skype, social media and custom-made software in the writing, rehearsal and final performance stages of the play.}

Springtime (Ankur Productions, 19 May 2012) combined traditional theatrical forms with digital technologies to articulate a culturally urgent investigation into social media and its ramifications, specifically the diverse acts of public protest (2011-2012) now often referred to as the "Arab Spring." Both Western and non-Western theatre have a long tradition of interrogating the core political and social practices of our lives, articulating what Collini [1] frames as 'relations of power in a given space.' Springtime demonstrates how live performance supported by social media is an appropriate space to articulate relations of power across and between complex, multi-dimensional channels of communication and culture. The Egyptian and Scottish actors involved in Springtime documented, via 'real' blogs and diaries, their own economic and personal struggles as well as the impact of being involved with the play on their lives. The production used technologies that echo those used by Egyptian demonstrators, such as blogs, tweets, fictional diaries, YouTube videos and Facebook; however, as in the protests, there are no clear-cut quantifications available to measure the direct impact or agency of social media. Rather, we frame the outcomes as a dialogue. Indeed, digitally mediated conversation has been identified as one of the core channels for non-violent protest, in which "In addition to enabling young people to organize, technology has facilitated the growing participation of women in political conversation" [2].

Research into Social Media and the Arab Spring yields confusing quantitative results, Howard et al. [2] propose conclusively that social media have been instrumental forces:

Social media was used heavily to conduct political conversations by a key demographic group in the revolution - young, urban, relatively well educated individuals, many of whom were women. Both before and during the revolutions, these individuals used Facebook, Twitter, and YouTube to put pressure on their governments. In some cases, they used new technologies in creative ways such as in Tunisia where democracy advocates embarrassed President Zine El Abidine Ben Ali by streaming video of his wife using a government jet to make expensive shopping trips to Europe [2].

While we cannot make quantitative claims for social media as vehemently as Howard et al. we concur that creative strategies have been significant and that Springtime was a form of digitally mediated creative protest. On the other hand, we take the point made by Stepanova that:

ICT and social media had little to do with the underlying sociopolitical and socioeconomic factors behind the protest movement. In Egypt, the sociopolitical gap between the small ruling elite and the bulk of the population had long reached critical levels, prompting most experts in the region to expect a major upheaval at some point. However, the fact that the crisis occurred sooner rather than later, in direct follow-up to protests in Tunisia, was largely due to the initial mobilizing effects of ICT and social media networks [3]

Social media is an ambivalent locus for dramaturgical intervention, with both dangers and potential benefits in framing it as an interface to 'live' performance. Springtime questions the authenticity of 'liveness' as a cultural and technological construct, while also asserting a positive claim to the potential of digital media as an agent for social change and inclusiveness in contemporary performance spaces.

The early narrative of the Arab Spring was often framed in technologically deterministic terms, a narrative in which social media such as Facebook and Twitter were cited as instrumental in engendering political change.

The apparent rapidity of this change was also attributed to the agency of online social mediation and to the 'liveness' of such media.

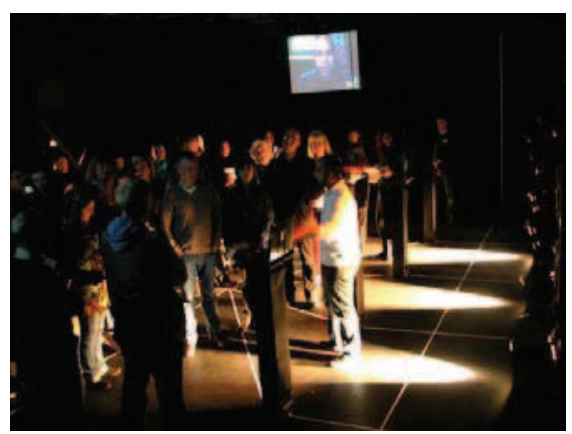

Fig. 1. Springtime, 2012. Mohammed Hagrassy talking via Skype to audiences in Glasgow. (C) Shabina Aslam. Photo: Ricardo Pardo.)

But we would like to interrogate this notion of 'liveness,' to ask whether the 'live' has ontological credibility or potency as a dramatic concept, whether it still has relevance or meaning in contemporary performance spaces, or, indeed, if the 'live' itself is a Utopian construct. Rehearsals as well as the final performance of Springtime were staged via Skype across different continents and timezones, emphasizing the contradictions of 'live' performance. If an actor in a Glasgow theatre space was 'live' to his or her 'live' audience, how did that notion translate to the audience in Cairo, for whom his/her performance was being transmitted via Skype, subject to the visual freezing and sonic fragmentation that are familiar to so many of us in holding online conversations? This question is further complicated by the addition, during the theatre performances, of prerecorded video material. Ausslander [4] articulates the ontological instability of 'liveness' raised by such intermingling of forms: "Whereas the audience for a recorded performance experiences it in the present while being aware that it is a repetition of the past, the audience witnessing live video in a performance may be more concerned with the spatial displacement of the image then with time-shifting" [4].

Springtime took place in the Tron's Studio Space, a traditional Black Box (Fig. 1). Eight laptops were placed on top of eight pedestals; these were placed in rows opposite each 
other like temple ruins. Our intention was to make the audience walk around the laptops seeking out the media. At either end of the space we suspended two screens. These were for the Skype images. No seating was available for the audience. Most entered the space baffled and confused about what they should be doing. Two laptops were used for Skype connections with actors and musicians in Alexandria, who played friends and relatives of the Egyptians in Glasgow. Six laptops showed prerecorded films, which were shown at appropriate moments in the play, the films showed scenes such as flashbacks - an argument in a hotel room, a couple running away through the streets of Glasgow. On arrival the audience was given programmes at the door, with basic information regarding the show. Many could not read these programmes as it was too dark. The lighting was arranged to create mystery, with lighting stands on either side of the theatre casting shadows on the central playing area. The audience (mixed members of the public who had not been to a theatre before as well as experienced visitors), whom we solicited feedback from via conversation afterwards, later told us they enjoyed being confused and not knowing what to expect.

Audience members also told us they initially thought the show was a series of random unrelated elements but realised eventually that there was a plot with characters and a story had unfolded. They thoroughly enjoyed the peeling back of the layers. The show was developed online via Skype conversations. Later all participants admitted to not really understanding how this would work but trusted each other and myself (Shabina Aslam) to deliver and guide them through the process. They stayed the course because they were intrigued and because we were honest with them about the issues we wanted to address: those of identity and the relationship of refugees and asylum seekers to their own countries and to the West. The characters that evolved included two Egyptian visitors to Scotland determined to stay illegally in the UK. The other Egyptian characters were more ambivalent about leaving Egypt. Two weeks prior to the performance we all met at the Ankur offices and decided on a video we would make that would enhance the narrative of two Egyptians disappearing in Glasgow. The two who 'dis-appeared' were Amina and Mohammed. We filmed them arguing with their partners amongst the whole group; they depicted their loneliness and feelings of being abandoned in Glasgow.

On the day of the show (19 May 2012) we had two Skype conversations, one Skype was for Amina and Mohammed pretending to be hiding out in a cupboard in Glasgow and the second Skype conversation was with the whole Egyptian group playing music that underscored the reading out of the diary pages in Glasgow and in Alexandria. The show was a mixture of fictional diary pages performed live in both locations, filmed content in Glasgow shown on the laptops and live musical performances from Egypt.

The two groups of Scottish Arabs and Egyptians created a response to contemporary events which unveiled as the performance progressed. The ripple effect of events across the globe can be felt as social media offers a way to bring the world closer, yet offers a cloak of anonymity. For many of the Scottish performers this was the first time that they had performed to a live audience. Their testimonies contributed to the video evidence of what happened on 4 May [Ankur Blog entry 29/05/2012; 5]. In both the development and final performance of Springtime, representation was negotiated between translocal actors, the Ankur director and staff and translocal audiences, for whom the multiple screens, dialogues and online narratives provided multiple points of entry into the performance and multiple vectors of narrative flow.

This was a strategy that was also reflected in the software developed by Eleanor Dare to support the actors in the earliest rehearsal stages of the performance. The heuristic software enabled actors to shift between characterisations, identities and timezones, by generating scenarios and characters for the actors to experiment with. Anecdotally, however, it proved unnecessary as the actors had many ideas and experiences to draw upon without the use of such software. We still feel the software has value for younger or inexperienced actors. (It was used for another 2012 Ankur production called "The Olympics of the Everyday").

\section{Conclusion}

I never thought I would ever see such a show in Glasgow. The pretty poetry and enchanting music, both calling for hope and freedom. The beautiful mix of old and new reminded me how truly Arab I am....It also reminded me how close I still am to the Middle East's revolutions, struggles and sacrifices. The artists looked as surprised as I am. Did they not expect to find Arabs here? [6]

The quote above from actor Mahir Hayatleh's Springtime diaries, evidences the impact of creative political articulation on its participants, both Egyptian and Egyptian-Glaswegian, not least upon the notion of identity. In an era of mass global communication and heterogeneous forms of mobility (a term that is itself highly contestable, but might include the relocation of refugees as well as the mass movement of migrant workforces), the notion of the site as well as the self becomes highly volatile. Springtime endeavored to work with technologies and events that are innately dynamic and unfixable; as such we assert here that they formed an integral and substantive aspect of the play's semantic frame. We conclude that this is a crucial aspect of creating an effective live interface, that the materiality and meaning of the medium should be intrinsic to the performance and its developmental processes. The use of live video streaming is not new, and this paper is not making claims for any particular technical innovation; instead we are asking what 'liveness' (for all its ontological contradiction and difficulty) can contribute towards the goals of widening participation and social change, within the specific context here of the Arab Spring and the Arab diaspora. We concur with Allagui and Kuebler who state "the use of ICT may be seen as the new 'technical' basis for reviving the phenomenon of mass, non-violent protest campaigns. This pattern is certainly one that merits further empirical and analytical investigation" [7].

\section{References and Notes}

* Based on a presentation at the first International Conference on Live Interfaces (ICLI), 7-8 September 2012, hosted by the Interdisciplinary Centre for Scientific Research in Music at the University of Leeds, U.K. See $<$ http://icli.lurk.org >.

1. Collini, S. "On Variousness; and Persuasion," New Left Review 27 (2004): 65-67, 2004.

2. Howard, P.N., Duffy, A., Freelon, D., Hussain, M., Mari, W. \& Mazaid, M. Opening Closed Regimes: What Was the Role of Social Media During the Arab Spring? (Seattle: PIPTI, 2011).

3. Stepanova, E. "Arab Spring” Implications Beyond the Region, PONARS Eurasia Policy Memo No. 159 (May 2011).

4. Ausslander, P., in Jefferies, Janis, Chatzichristodoulou, Maria and Zerihan, Rachel. Interfaces of Performance - Digital Research in the Arts and

Humanities (Aldergate: Ashgate Publishing, 2009).

5. Ankur Productions website available at:

<www.ankurproductions.org.uk/\#/about-us/vision>. Accessed 17/07/12.

6. Mahir Hayatleh, actor, Springtime diaries, 2012.

7. Allagui, I. and Kuebler, J. 2011 "The Arab Spring and the Role of ICTs," International Journal of Communication 5 (2011), Feature 1435-1442. 